\title{
Perceptions, attitudes, and practices towards research among resident physicians in training in Saudi Arabia
}

H.A. Mitwalli, ${ }^{7}$ K.M. Al Ghamdi ${ }^{1}$ and N.A. Moussa ${ }^{2}$

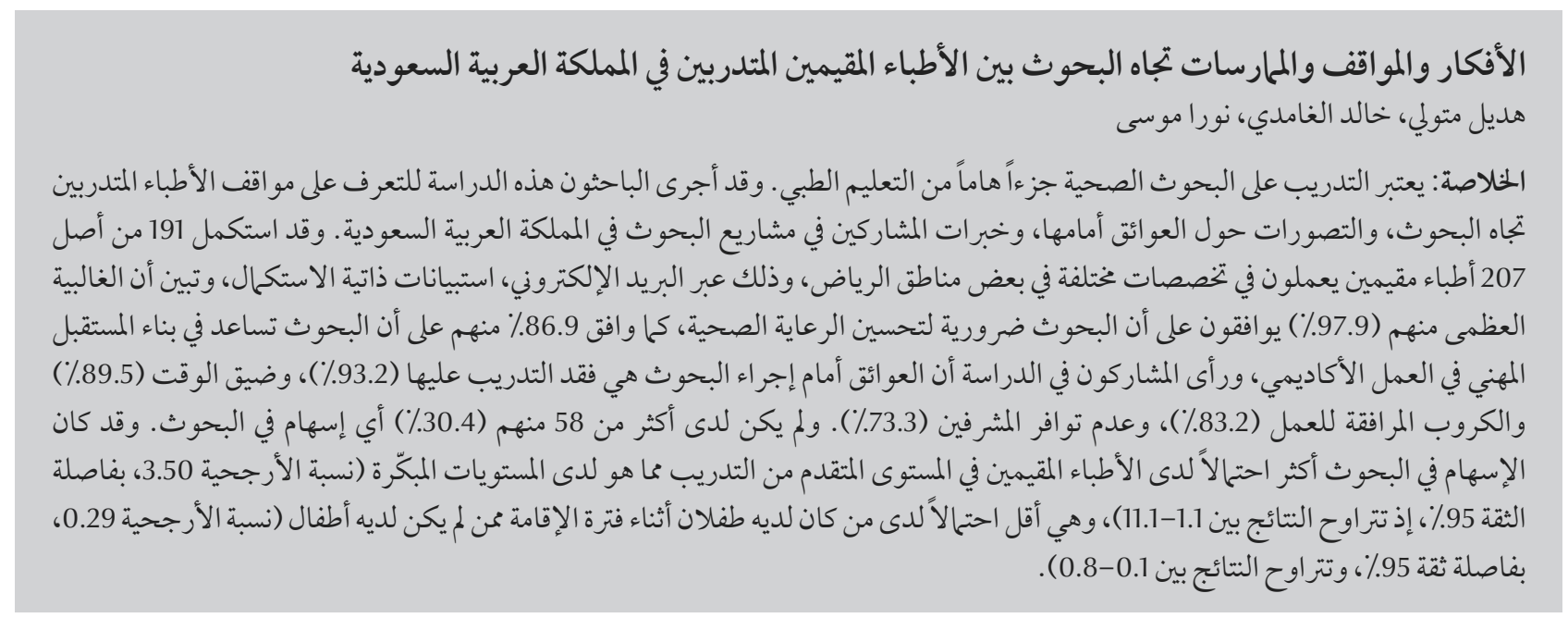

ABSTRACT Health research training forms an important part of medical education. This cross-sectional study examined the attitudes to research, perceived barriers to research and experience of participation in research projects among resident physicians in Saudi Arabia. A self-administered email questionnaire was completed by 191/207 residents working in different specialties and regions of Riyadh. A majority (97.9\%) agreed that research is essential and improves health care and $86.9 \%$ that it helps in building a future academic career. Lack of research training (93.2\%), lack of time (89.5\%), work-related stress (83.2\%) and lack of supervisors (73.3\%) were perceived barriers to doing research. Only 58 (30.4\%) had had any research involvement. Involvement in research was significantly more likely for residents at an advanced level of training than at earlier levels (OR 3.50, 95\% Cl: 1.1-11.1) and less likely for those who had 1 or 2 children during residency than those who had none (OR 0.29, 95\% Cl: 0.1-0.8).

Perceptions, attitudes et pratiques vis-à-vis de la recherche chez des médecins internes en formation en Arabie saoudite

RÉSUMÉ La formation à la recherche en santé représente une partie importante des études de médecine. La présente étude transversale a étudié les attitudes de médecins internes en Arabie saoudite vis-à-vis de la recherche, des obstacles perçus et de leur expérience en matière de participation à des projets de recherche. Un autoquestionnaire envoyé par courrier électronique a été rempli par 191 médecins internes sur 207 travaillant dans différentes spécialités et régions de Riyad. La majorité (97,9\%) convenait que la recherche était essentielle et améliorait les soins de santé et $86,9 \%$ des médecins étaient d'accord pour affirmer qu'elle contribuait à l'établissement d'une future carrière académique. L'absence de formation à la recherche (93,2\%), le manque de temps (89,5\%), le stress lié au travail (83,2\%) et l'insuffisance de l'encadrement (73,3\%) étaient les obstacles perçus à la pratique de la recherche. Seuls 58 internes $(30,4 \%)$ avaient été impliqués dans des travaux de recherche. Une participation à des travaux de recherche était nettement plus probable chez les internes à un stade avancé de formation par rapport aux niveaux moins avancés (OR 3,50; IC à $95 \%: 1,1-11,1)$ et moins probable chez ceux qui avaient eu un ou deux enfants pendant leur internat par rapport à ceux qui n'en avaient pas eu (OR 0,29; IC à $95 \%$ : 0,1-0,8).

'Department of Dermatology, College of Medicine; ${ }^{2}$ King Saud University, Riyadh, Saudi Arabia (Correspondence to K.M. Al Ghamdi: kmgderm@yahoo.com).

Received: 22/02/12, accepted: 22/07/012 


\section{Introduction}

Health research is essential to improving health care in all countries of the world. Training in health research forms an important part of medical education [1], while students' research can contribute to the published output of an institution. It is essential to inculcate critical thinking and reasoning skills and to develop a positive attitude among resident physicians towards their scientific research during their medical career [2].

Not all trainees, however, wish to take time out of clinical training to do research. It is important therefore to ensure that opportunities for research are integrated with clinical duties so that adequate research training is provided during a trainee's higher medical education [3]. Exposure to a period of research training within a clinical programme can be a springboard for exploring more substantial career options. Furthermore, the creation of a researchoriented culture among future clinical leaders is as important as recruiting future academic leaders, as will help to create an environment where both can flourish [3-6]. There is a general consensus, however, that clinical academic medicine is in crisis. A growing sense of disconnection between research and clinical practice, plummeting numbers of clinical lecturer posts and closure of clinical academic departments are all signs of the malaise $[7,8]$. A lack of suitably trained and qualified clinical academic staff has been highlighted as a major factor in this crisis [9].

Saudi Arabia is undergoing a transformation in health care for the population. We believe that it is essential to allocate resources to basic and clinical research in Saudi Arabia to meet the escalating health care needs of our changing demographic pattern. This is a large and complex challenge, which calls for collaboration between scientists and clinicians from various disciplines. Yet it is extremely important to evaluate whether efforts and interventions to promote research are paying off. The objective of the current study was to assess the attitudes and practices towards research among resident physicians in training in Saudi Arabia and to investigate barriers to conducting research. It was hoped that the results would help in identifying difficulties and challenges faced by residents while pursuing research during residency, which can help later on in building research-facilitating curricula and environments into residency programmes.

\section{Methods}

\section{Study design and sample}

The present study was a cross-sectional survey of medical residents engaged in postgraduate programmes in various health specialties in Riyadh, Saudi Arabia from May to June 2011. A questionnaire was sent to all the residents registered with the Saudi Council of Health Specialty Programs. In the email message residents were invited to participate, with assurances that the results would be kept confidential and that participants' names would be entered into a prize draw for a laptop computer. Residents were asked to express their own views and not what they thought was ideal.

\section{Data collection}

We designed an online questionnaire to collect the data. The first page of the questionnaire contained a short description on the aim of the study and how to fill in the questionnaire. The residents were asked to fill in the questions according to what they think and practice and not to what should ideally be done.

The questionnaire asked residents for their views about whether research is essential in the practice of medicine, postgraduate medical trainees should participate in research and teaching research methodology should be a part of their residency curriculum. The survey contained a section about the practices of residents towards medical research in which they were requested to answer whether their residency training programme required them to complete a research project before graduation, whether they had completed a research project during their residency (if yes, how many research projects had been completed but not necessarily published) and whether they had participated or contributed in any way to a research project (if yes, the type of research project, number of hours per week spent on their research during the last 12 months, what their contribution was and their experience of presenting their research during the residency training period). The survey also solicited information about the barriers that residents might face as well as the motives that might encourage them to conduct a research project. The response options utilized a 5-point Likert scale and the responses to the question about residents opinion about research was as follows: $1=$ strongly agree, 2 = agree, 3 = neutral, 4 = disagree, $5=$ strongly disagree.

The final part of the questionnaire collected sociodemographic information about the residents, including age, sex, marital status, number of children, specialty, level of training and training centre/city.

The survey was pilot-tested on 30 residents to estimate the time required to complete the questionnaire and to determine the comprehensibility of questions so that it could be refined accordingly. Pilot questionnaires were excluded from the final analysis. The final self-administered questionnaire consisted of 26 questions, which required approximately 5 minutes to answer. This study was approved by the local ethics committee.

\section{Statistical analysis}

SPSS, version 16 was used for statistical analysis. Numerical variables are 
reported as mean and standard deviation (SD). The chi-squared test was used to assess associations between different categorical variables. Multiple logistic regression was used to relate residents' attitude and practices towards research with various sociodemographic variables, including age, sex, marital status, specialty and level of training. The statistical significance was based on $P$-value $<0.05$.

\section{Results}

\section{Demographic data}

Of the total of 207 residents who were contacted and reminded 191 returned complete answers, a response rate of $91.7 \%$. The respondents included 128 males $(67.0 \%)$. The mean age was 30 (SD 4.6) years, range 20-49 years. A majority were married (71.7\%) and the median number of children they had was 1 (range 0-5). Most respondents were in a medical specialty (41.8\%) or surgical specialty (40.3\%) while $18.3 \%$ were in non-clinical specialties. A total of $27.2 \%$ were at the beginning of their residency, while $46.0 \%$ were at the middle of their residency and $26.1 \%$ were senior residents. Half the residents (50.2\%) were from the Central region, $14.6 \%$ from the Western region, 27.2\% from the Eastern region, $1.6 \%$ from the Northern region and $5.8 \%$ from the Southern region of Saudi Arabia.

\section{Attitudes towards research}

The majority of the 191 residents (97.9\%) agreed that research is essential in the practice of medicine and $92.2 \%$ also agreed that residents in training should participate in research and 93.7\% that teaching research methodology should be a part of the residency curriculum. Additionally, 92.7\% agreed that research promotes critical thinking, 93.2\% that research improves health care and $86.9 \%$ that research helps further their career.
The responses to a list of perceived barriers to conducting research varied widely and included lack of research training (93.2\%), lack of allocated research time (89.5\%), work-related stress $(83.2 \%)$ and lack of supervisors (73.3\%) (Figure 1). According to the respondents, factors that might encourage them to do research during residency included: to improve their research skills (93.7\%), to have research published (91.6\%), to add a positive achievement to their resume (89.5\%), to fulfil research interests (88.5\%), to facilitate acceptance in a subspecialty fellowship programme (79.6\%) or because it was mandatory in the residency programme (63.9\%).

\section{Research practice among residents in training}

Of the 191 residents who responded, 58 (30.4\%) had participated in research during their residency, while 133 (69.6\%) had not. Residents who were in an advanced level of training were significantly more likely to have conducted research than those who were in early residency (OR 3.50, 95\%
CI: 1.1-11.1). Residents who had 1 or 2 children during residency were less likely to have completed research in comparison to those with no children (OR 0.29, 95\% CI: 0.1-0.8) (Table 1). There was no significant association between the proportion of residents conducting research projects and age, sex and marital status or by medical specialty or training centre region.

Of the 58 residents who had participated in research during their residency programmes $53.4 \%$ had contributed to the concept (design) of the research, $63.8 \%$ to a literature review, $46.6 \%$ to writing a proposal, $55.2 \%$ to execution of experiments, $46.6 \%$ to data entry, $32.8 \%$ to data analysis and $44.8 \%$ to writing a manuscript. The types of research projects in which residents had participated included case reports (34.5\% of physicians), retrospective clinical studies (32.8\%), literature reviews $(20.7 \%)$, cross-sectional studies (13.8\%), prospective clinical studies (12.1\%), basic science projects (8.6\%) and clinical trials (8.6\%) (Figure 2).

The median number of hours that residents spent on their research



Figure 1 Barriers to conducting research by residents according to the 191 study residents 


\begin{tabular}{|c|c|c|c|c|c|c|}
\hline \multirow[t]{3}{*}{ Variable } & \multirow{3}{*}{$\begin{array}{l}\text { Total } \\
\text { No. }\end{array}$} & \multicolumn{5}{|c|}{ Completed research project during residency (Yes/No) } \\
\hline & & Yes & $\begin{array}{l}\text { Unadjusted OR } \\
\qquad(95 \% \mathrm{CI})\end{array}$ & $P$-value & $\begin{array}{l}\text { Adjusted OR } \\
\qquad(95 \% \mathrm{Cl})\end{array}$ & $P$-value \\
\hline & & $\%$ & & & & \\
\hline \multicolumn{7}{|l|}{ Age (years) } \\
\hline$\leq 27$ (ref.) & 32 & 21.8 & 1.00 & - & 1.00 & - \\
\hline $28-29$ & 103 & 32.6 & $1.73(0.7-4.2)$ & 0.23 & $1.51(0.5-4.9)$ & 0.50 \\
\hline $30+$ & 56 & 34.6 & $1.89(0.9-4.2)$ & 0.11 & $1.14(0.3-3.9)$ & 0.84 \\
\hline \multicolumn{7}{|l|}{ Sex } \\
\hline Male & 128 & 31.3 & $1.18(0.6-2.4)$ & 0.64 & $1.32(0.5-3.3)$ & 0.55 \\
\hline Female (ref.) & 63 & 27.8 & 1.00 & - & 1.00 & - \\
\hline \multicolumn{7}{|l|}{ Marital status } \\
\hline Married & 137 & 32.1 & $1.46(0.7-3.2)$ & 0.33 & $1.41(0.4-4.5)$ & 0.56 \\
\hline Unmarried (ref.) & 54 & 24.4 & 1.00 & - & 1.00 & - \\
\hline \multicolumn{7}{|l|}{ Specialty } \\
\hline Medical related & 79 & 23.7 & $0.59(0.2-1.5)$ & 0.59 & $0.85(0.3-2.5)$ & 0.77 \\
\hline Surgical related & 77 & 35.1 & $1.00(0.4-2.5)$ & 0.94 & $1.02(0.3-3.0)$ & 0.97 \\
\hline Non-clinical (ref.) & 5 & 34.4 & 1.00 & - & 1.00 & - \\
\hline \multicolumn{7}{|l|}{ Level of training } \\
\hline Early residency & 52 & 24.0 & 1.00 & - & 1.00 & - \\
\hline Mid-residency & 88 & 20.2 & $0.80(0.3-1.9)$ & 0.61 & $0.56(0.2-1.5)$ & 0.24 \\
\hline Advanced residency (ref.) & 50 & 54.2 & $3.70(1.6-8.9)$ & 0.003 & $3.50(1.1-11.1)$ & 0.03 \\
\hline \multicolumn{7}{|l|}{ Training centre region } \\
\hline Central & 99 & 34.1 & $1.89(0.5-7.3)$ & 0.35 & $1.78(0.4-8.0)$ & 0.45 \\
\hline Western & 28 & 40.7 & $2.52(0.6-11.2)$ & 0.22 & $2.78(0.5-14.8)$ & 0.23 \\
\hline Eastern & 52 & 20.0 & $0.92(0.2-3.9)$ & 0.91 & $0.89(0.2-4.5)$ & 0.89 \\
\hline Northern and Southern (ref.) & 14 & 21.4 & 1.00 & - & 1.00 & - \\
\hline
\end{tabular}

$O R=$ odds ratio; $C l=95 \%$ confidence interval; $($ ref. $)=$ reference category.

projects every week was 1 hour (range 0-21 hours per week). The 58 residents participating in research had presented their research during their residency period in an oral presentation (37.9\%) or in a poster presentation (20.7\%), while $10(17.2 \%)$ had published research papers.

\section{Discussion}

Our study focused on the attitudes and practices of medical residents in training towards research. Research during residency may not only foster interest in an academic career but may also make residents more competitive for future fellowships, other academic positions and office-based research [10]. Research training in Saudi Arabia is currently being incorporated as part of medical school curricula and residency training programmes to build a base of competent physician scientists. Medical education intends to prepare physicians to meet the challenges of practice by fulfilling their roles of clinicians, educators and clinical researchers [11].

Published data about residents' attitudes toward research during training in a range of specialties suggest that not all residents are enthusiastic about doing research during residency and that some do not value research as a useful academic exercise [10-20]. This is in contrast to our results, which indicated that the great majority of the participating residents were enthusiastic about research and believed that residents must participate in research. In our study, $93.7 \%$ believed that research should be a mandatory part of the residency curriculum. Unfortunately, this did not reflect on the actual practice of research among these residents in Saudi Arabia, as less than one-third of the responding residents (30.4\%) had conducted research during residency.

The participation rate in research in our study can be compared with a study from Pakistan performed on residents in paediatrics, in which $92 \%$ reported participation in research before entering residency but only $18 \%$ reported involvement in research during residency. Furthermore, $96.8 \%$ of 


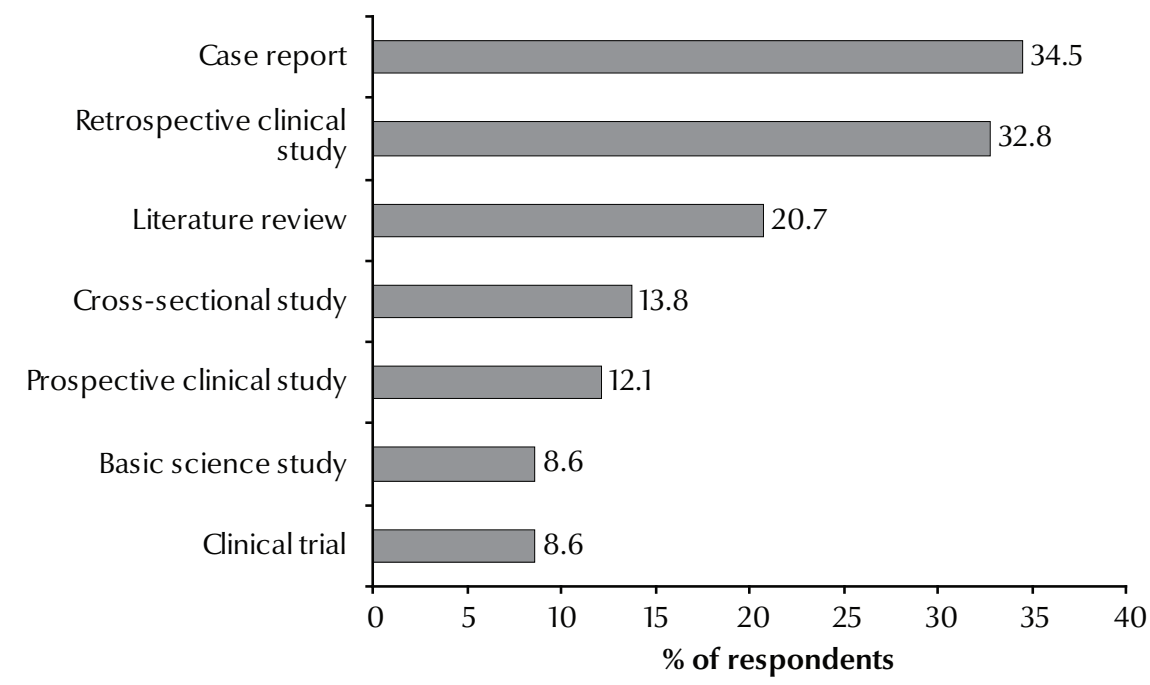

Figure 2 Types of research projects in which the 58 study residents had participated

those respondents believed that lack of time was a reason behind this. Other influences included lack of availability of mentors (72.7\%) and funding (62.8\%) [10]. In our study the main perceived barriers to conducing research by residents included lack of research training (93.2\%), lack of allocated research time (89.5\%), work-related stress (83.2\%) and lack of supervisors (73.2\%). In a study performed on anaesthesiology residents in Canada, $67 \%$ had been or were involved in a research project during the time of the survey [20]. Only $41 \%$ believed that research during residency should be mandatory. Obstacles preventing residents from participating in research included schedule conflicts, inadequate mentor availability and lack of time [20]. Obstacles cited to successfully completing research in a similar Canadian study included lack of time (68\%), lack of interest (31\%) and faculty's lack of interest (20\%) [15].

It seemed that the most common types of research projects in which residents participated in our study were case reports (34.5\%) and retrospective clinical studies $(32.8 \%)$. This reflects the problem of too few types of projects available for residents' participation. The modes of presenting their research work included oral presentations (37.9\%), poster presentations (20.7\%) and published papers
(17.2\%). This highlights the issue of insufficient resident's participation at conferences and seminars.

Research is important for progress towards better health care. Crucial steps must be taken to encourage residents to engage in research. The uniformity of the obstacles faced by residents is obvious from studies performed in several countries. Overcoming those obstacles is the key to encouraging residents to participate in research. Research training must be a part of every residency programme. Participating in research projects during residency should be mandatory for all residents in various fields and programmes. Residency programmes should allocate time for research. Also, the lack of mentors and supervisors should be solved by assigning research supervisors for residents. Funding opportunities and resources for attending academic conferences should be increased, which would help in exposing residents to ongoing research.

To the best of our knowledge, this study is the first to evaluate the perceptions, practices and attitudes toward research among physician residents in training in the Middle East. We addressed a previously neglected issue to find ways in overcoming obstacles that challenge medical residents, which could lead to increased involvement of residents in research.

Competing interests: None declared.

\section{References}

1. Scaria V. Whisking research into medical curriculum: the need to integrate research in undergraduate medical education to meet the future challenges. Calicut Medical Journal, 2004; 2 :el.

2. Aslam F, Shakir M, Qayyum MA. Why medical students are crucial to the future of research in South Asia. PLoS Medicine, 2005, 2:e322.

3. Reinders JJ, Kropmans TJ, Cohen-Schotanus J. Extracurricular research experience of medical students and their scientific output after graduation. Medical Education, 2005, 39:237.

4. Hren D et al. Teaching research methodology in medical schools: students' attitudes towards and knowledge about science. Medical Education, 2004, 38:81-86.

5. Khan $\mathrm{H}$ et al. Knowledge and attitudes about health research amongst a group of Pakistani medical students. BMC Medical Education, 2006, 6:54-60.
6. Myint PK, MacLullich AM, Witham MD. The role of research training during higher medical education in the promotion of academic medicine in the UK. Postgraduate Medical Journal, 2006, 82:767-770

7. Clark J, Smith R. BMJ Publishing Group to launch an international campaign to promote academic medicine. British Medical Journal, 2003, 327:1001-1002.

8. MacLullich AM, Witham MB, Myint PK. Developing a research website for trainees. BMJ Career Focus, 2005, 330:98.

9. Bell J; Working Group of Academy of Medical Sciences. Resuscitating clinical research in the United Kingdom. British Medical Journal, 2003, 327:1041-1043.

10. Khan H, Khan S, Iqbal A. Knowledge, attitudes and practices around health research: the perspective of physicians-intraining in Pakistan. BMC Medical Education, 2009, 9:46. doi: 10.1186/1472-6920-9-46. 
11. Ullrich $\mathrm{N}$ et al. Research during pediatric residency: predictors and resident-determined influences. Academic Medicine, 2003, 78:1253-1258.

12. Logan PM. Resident research in Canadian radiology training programs. Annals of the Royal College of Physicians and Surgeons of Canada, 1998, 31:233-235.

13. McCrindle BW, Grimes RB. Will pediatric residents do research? A survey of residents' attitudes. Annals of the Royal College of Physicians and Surgeons of Canada, 1993, 26:283-287.

14. Buschbacher R, Braddom RL. Resident versus program director perceptions about PM\&R research training. American Journal of Physical Medicine and Rehabilitation, 1995, 74:90-100.

15. Gill $S$ et al. Obstacles to residents' conducting research and predictors of publication. Academic Medicine, 2001, 76:477.
16. Temte JL, Hunter PH, Beasley JW. Factors associated with research interest and activity during family practice residency. Family Medicine, 1994, 26:93-97.

17. Morris BA, Kerbel D, Luu-Trong N. Family practice residents' attitudes toward their academic projects. Family Medicine, 1994, 26:579-582.

18. Fitz-Gerald MJ et al. Psychiatry residents' participation in research: a survey of attitudes and experience. Academic Psychiatry, 2001, 25:42-47.

19. Gay SB, Hillman BJ. Evaluation of a mandatory radiology resident research rotation. Academic Radiology, 2000, 7:172-175.

20. Silcox LC et al. Residents' and program directors' attitudes toward research during anesthesiology training: a Canadian perspective. Anesthesia and Analgesia, 2006, 102:859-864. 